\title{
Does Employer Brand Matter: An Empirical Study on Online Job Reviews, Social Media Usage and Firm Performance
}

\author{
Lorin Hitt \\ University of Pennsylvania \\ 1hitt@wharton.upenn.edu
}

\author{
Fujie Jin \\ Indiana University \\ jinf@indiana.edu
}

\author{
Bowen Lou \\ University of Connecticut \\ bowen.lou@uconn.edu
}

\begin{abstract}
We examine how employee-contributed job reviews and firm-managed social media posts jointly build up "employer brand" as an intangible asset and influence market valuation. Using large-scale data of job reviews, social media posts and firm performance, we study how employer band can create value distinct from overall corporate (consumer) branding. We find that more positive job ratings are associated with higher firm market value, particularly in labor-intensive industries and especially for positions which are harder to replace and have higher employee mobility. In addition, firms can respond and complement this effect by posting more employee-related content on their social media pages. Overall, our results suggest that firms should have coordinated strategies across digital platforms, presenting a consistent employer brand, to maximize their market valuation.
\end{abstract}

\section{Introduction}

As the recruiting market turns more candidate-driven, employees are gaining more power in the labor market. One notable example is recent artificial intelligence (AI) hiring frenzy across various industries. It is estimated that fewer than 10,000 people worldwide have necessary skills to tackle AI-related research challenges. ${ }^{1}$ Employees have the opportunity to "shop around" for more job opportunities from a variety of firms. The result is an escalation of recruiting and retention costs above and beyond the effects on wages. ${ }^{2}$ Recruiters and human resource personnel have recognized that they can increase the returns to their recruiting investment by managing their "employer brand", or "the package of functional, economic and psychological benefits provided by employment, and

\footnotetext{
${ }^{1}$ https://www.nytimes.com/2017/10/22/technology/artificialintelligence-experts-salaries.html

${ }^{2}$ http://blogs.wsj.com/cio/2016/10/05/the-skills-gap-is-nolaughing-matter/
}

identified with the employing company" [1] similar to the way consumer brands reflect and convey similar concepts related to product characteristics.

A strong employer brand can act as another asset for firms in the sense that it involves a sequence of investments by the firms to create a future stream of benefits. For instance, firms invest in creating an attractive work environment, offering higher quality of life benefits and opportunities for career development. In return, it is believed that a strong employer brand is associated with attracting more applicants for open positions, and improves employee retention which reduces cost and preserves firm specific human capital $[2,3]$. To the extent that the employer brand behaves as an asset, it can be reflected in increased market value, even if it does not appear as a capital asset on the balance sheet. This relationship is similar to that associated with consumer brand $[4,5]$.

Part of the increased interest in employer branding is the popularity of online career platforms. The platforms allow job applicants to observe evaluations on job positions at each firm contributed by current or previous employees. The evaluations of employers by their employees provide an opportunity to observe and quantify employer brand [6]. The platforms also have a wealth of historical data on the attributes of firms and their employees, which can be linked with financial data to study the effect of employer brand on firm performance.

In addition to job reviews contributed by employees, firms' social media pages represent another source of information for job applicants and could be another avenue for building employer brand. Increasingly, firms are recognizing the importance of social media in connecting with their employees and building relationships. Intuit, for example, has an additional Facebook page specifically designed for posting employee-related information. ${ }^{3}$ Social media not only provides opportunities for firms to directly communicate with potential employees, but its interactive nature

\footnotetext{
${ }^{3}$ https://www.facebook.com/intuitlife/
} 
also allows such content to be enhanced organically by participation of current, former and prospective employees to more effectively convey firm culture, employee work-life, and career development. These communications have considerable variety, ranging from activities within the firm to support daily work such as the employee standup meeting at MTS Systems (Figure 1) - to social, external activities such as the activities of Microsoft's corporate soccer team (Figure 2). At a minimum, social media provides an additional signal of employer brand and a more precise measure of employer characteristics. The net result is that job reviews and effectively managed social media can be reinforcing. But there could also be other possibilities that social media may simply be uninformative leading to no effect, and job reviews may also create the opportunity for disconfirmation of perceptions created on social media which can have a negative effect.

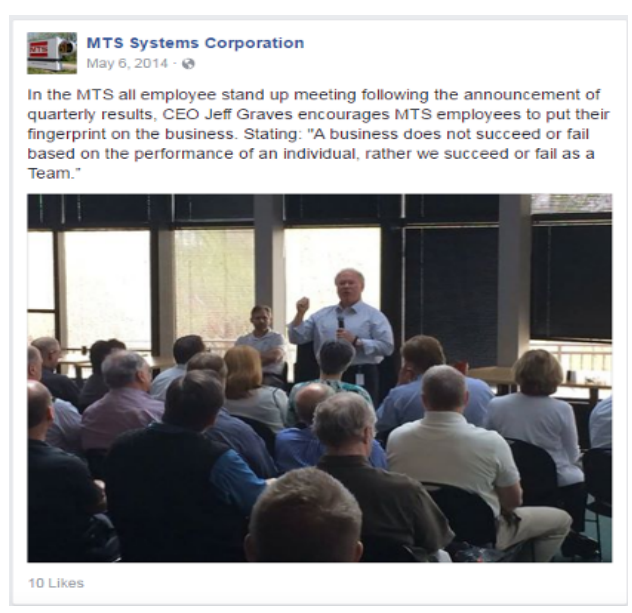

Figure 1. MTS employee standup meeting

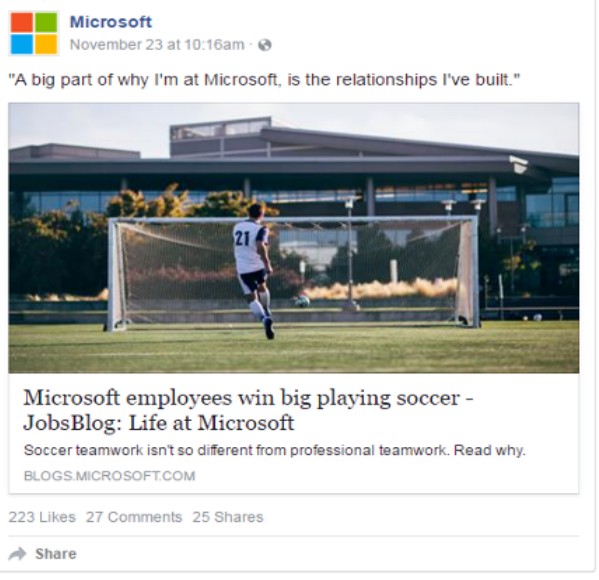

Figure 2. Microsoft soccer team
In this study, we compile a unique panel by combining job reviews from a prominent online job review platform, social media activities from Facebook (distinguishing employee-focused activity) and firm financial performance data from Compustat. Applying market value estimation models to our panel data, we find that job reviews are positively related to market value and their effects are much greater for occupations in information technologies (IT) and research and development (R\&D) where employees are difficult to recruit and retain. While we do not find employee-targeted social media activities have any direct beneficial effect, such activities can enhance the value of favorable job reviews - that is, they behave as if they are complementary. Our findings suggest that 1) employer brand acts as an intangible asset, enhancing market value, 2) social media activities, especially employee-focused ones, can further improve this value, but 3) not all firms can benefit equally because the ability to use social media to enhance their employer brand depends on having a valuable brand in the first place.

To the best of our knowledge, this study is the first to examine the interaction of multiple channels of information on employer brand and its influence on firm value, drawing on previous literature on product reviews $[7,8,9,10,11]$, technology-related intangibles [12] and economic impacts of employee satisfaction [13]. In contrast to prior studies on the technology and labor markets, our study focuses on general job markets rather than temporary outsourcing platforms $[14,15]$ and adds the complementary role of social media that has not been considered in the emerging literature on the economic effects of job reviews [16, 17]. This is particularly important as firms can also benefit from investments in the direct communication of characteristics as employers beyond simply creating them for their employees.

\section{Theory}

\subsection{Job Reviews and Employer Brand}

Prior literature has shown that online product ratings and reviews have significant impacts on product demand $[18,7,8,9,11]$. Analogously, favorable ratings on employee job satisfaction likely affect firm performance and recruiting success [16]. Product reviews address the information asymmetry between product sellers and customers, especially for experience goods. In a similar vein, job positions are also experience goods and there is information asymmetry between employers and job candidates for which job reviews can potentially mitigate. However, the way 
that these reviews influence decision makings can be quite different. Product purchases are mostly one-time decisions and have limited downside risk because they involve little relationship-specific investments and are typically reversible (with options to return or exchange). In contrast, employment decisions have considerable switching costs and substantial downside risk if employees switch jobs too frequently. This is true even for unemployed individuals who incur job-specific moving and training costs for starting a new job [19]. Thus, the employer brand is likely to have greater influence on job decisions than the product brand has on purchase decisions.

Employer brand is likely correlated with the corporate brand or product brand, since more recognizable firm names could make the employer a more attractive place to work. However, a general corporate brand is not the same as an employer brand. For example, large corporations with strong brand names can still have unattractive employer characteristics such as limitations in benefits, work environment or promotion opportunities, and the importance of these attributes may vary across prospective employees. ${ }^{4}$ A prior study by LinkedIn [20] highlights a number of reasons why employer brand and customer brand are distinct including the fact that greater expenditure on employees leads to higher costs that may make products less attractive, and shows that employees need not be customers. There can also be a disconnect between work practices that maximize production and employee preferences. For instance, "high performance work practices" such as employee empowerment and discretion that have been hypothesized to be favorable to employees may work better for customized products than mass produced products [21], and some employees may prefer a low discretion environment regardless [22]. Accordingly, the factors that result in high firm value through product market success may not make the firm a more attractive place to work.

\subsection{Job Reviews and Market Value}

Employer brand can be valuable because it directly reflects current attributes contributing to labor market success as well as the cumulative effect of past decisions forming an employer's reputation to have an attractive work environment $[23,24]$. We expect to observe that firms with stronger employer brand can be related to higher increases in market value, if employer brand acts as an intangible asset. Prior work has indicated that

\footnotetext{
${ }^{4}$ See for example: http://www.forbes.com/sites/ericjackson/ 2011/12/14/top-ten-reasons-why-large-companies-fail-to-keep-their -best-talent/\#2f66267f6af7
}

better employee satisfactions are correlated with higher shareholder returns [13]. It is also believed that a strong employer brand can lower recruiting and retention costs, or increase labor quality by expanding the applicant pool $[2,3]$. These can lead to a positive association between employer brand and market value as investments in employer brand would be expected to generate a stream of benefits over time in lower costs [25].

One mechanism linking employer brand to market value is a reduction in employee turnover, an important driver of overall firm performance [26]. Job hopping represents a potential loss of firm knowledge [27], and can create adverse competitive spillovers if departing employees transfer this knowledge to competitors. In addition to the direct effect of the loss of an employee, departing employees may cause others to leave, resulting in small changes in work environment but having an unusually larger effect on turnover [28]. It is suggested that turnover is heavily influenced by perception of employment conditions with people switching jobs when they perceive a gap between desired and current employment conditions [29, 30]. Even conditional on actual employment conditions, positive reviews and high ratings of a firm relative to competitors may reduce the expected gain from job switching and thus lead to increased retention and greater associated benefits to enhance firm performance [31].

Even if a firm's employer brand has measurable benefits, the net effect of the employer brand on firm value can still be ambiguous. For instance, the cost of the strategies needed to create and promote the employer brand may equal or exceed the benefits. The depreciation rate of employer brand can be sufficiently high such that it requires continual reinvestments and is therefore an expense rather than an asset. Possibly, neither the costs nor benefits are substantial enough to make a material difference in overall firm market value even if it has a positive net present value, or that job reviews are too noisy to provide a reliable measure of employer brand. Therefore, we need to first demonstrate empirically the relationship between job reviews and firm market valuation. Thus, we posit:

Hypothesis 1: Firms with stronger employer brand (as measured by job reviews contributed by employees) have a higher market value.

\subsection{Job Reviews, Social Media and Market Value}

Employees usually resort to different sources to gain information about working conditions at their current employer and other potential employers. Of 
particular interests are those settings where a firm can influence the information that is available, providing an instrument for helping the firm manage their employer brand (other than simply providing more attractive working conditions). One important source of employer information is social media. Social media has been increasingly adopted and advocated by firms to transform their business practices and enhance financial performance $[32,33,34]$. The content posted on social media has shown firms' engagement with customers who purchase their products and services $[35,36]$. Many companies have also invested in their employment-related social media presence even though social media by itself may not be specifically tailored towards employment management.

Our study focuses on firm interactions on Facebook since it is one of the most widely used general social media service and provides capabilities for firms to communicate with existing and potential stakeholders (through company pages). While managing an effective social media presence may require significant investment, there is no barrier that prevents firms from engaging potential employees on social media and such interactions may be less costly to facilitate than through the traditional recruiting process that can cost more for some types of employees. However, one limitation of this approach is that employer-generated content may have a differential impact than user-generated content [37]. Nonetheless, even if employers view social media posts with skepticism, a general presence online and in social media may encourage greater engagement in other platforms such as job review sites and may influence the valence of the reviews.

The simple way in which the firm-managed social media posts and user-generated reviews interact is by providing multiple, at least partially independent signals of firm quality. If signals obtained from social media and employee reviews provide useful but imperfect information, the aggregation of multiple sources of information can decrease uncertainty, providing better information to potential employees [23]. This may even be the case and perhaps more important if some signals are biased or inaccurate, either due to the fact that social media activities may be "cheap talk" or firms or its competitors may engage in forum manipulation $[38,39,40]$ as the ability of users to compare multiple information sources may allow them to correct for misinformation, and may decrease incentives to engage in deceptive behavior in the first place. Overall, we expect to see that better job reviews interacting with more employee related social media posts could together build stronger employer brands for firms. We therefore hypothesize that online social media and job reviews can be complementary, greater employment-related activities in social media channels being more valuable in firms that have favorable online perception in reviews:

Hypothesis 2: Firms with greater employee-related social media activity have an increased value of favorable job reviews (that is, they are complementary).

\section{Data and Empirical Strategy}

\subsection{Data and Measurement}

The panel data for our empirical study is constructed from three primary sources: 1) ratings and reviews on job positions from a prominent online job review platform, 2) social media activities from firm Facebook pages and 3) company financial information from the Compustat database. The final compiled panel consists of annual data for 2,567 publicly traded companies across eight years (2008-2015).

Job Reviews Data: Employees post reviews of their work experience on the platform. The job review data includes an overall job rating on a scale of one to five stars, categorical ratings on specific aspects of employment, as well as a detailed narrative review. We also have metadata about the review, including the date when the review was entered and demographic information of the reviewer including their employment status (currently or previously employed at the firm), job title, length of employment and compensation.

We construct the main independent variable $J o b$ Ratings as an average of the "star ratings" for all job positions associated with the firm in each year. We also examine the fraction of favorable (4 or 5 stars) or unfavorable ( 1 or 2 stars) ratings $[18,7,9]$. The ratings are also divided into five detailed sub-categories: career opportunities, compensation and benefits, culture and values, work/life balance, and senior management. These sub-categorical ratings offer more informative indicators of a firm's employer brand. As the ratings in each sub-category can be correlated with each other and measure the same underlying construct of employer brand, we construct an additional variable as the first principal component of these sub-categorical measures (Job Rating, CombCateg).

Social Media Data: We examine corporate Facebook usage for alternative sources of information that might influence employer brand. We begin by using Facebook's search box to look up the corresponding page for each company name, ${ }^{5}$ and record all the posts on the page. The timestamp on each post allows us to aggregate the total number of Facebook posts published in each year. Next, we perform textual analysis to

\footnotetext{
${ }^{5}$ Facebook's Graph API is also used for our data collection.
} 
determine whether these posts are employment-related. We first create a lexicon of employee-related words, using the corpus of the full text job reviews. We adopt Latent Dirichlet allocation (LDA) for this lexicon [41]. Indeed, the topics generated from our text mining approach match closely with the five subcategories of job experience. Moreover, the words within topics identified from job reviews can be applied to classify social media posts for employee-related content.

We follow the standard text preprocessing procedure to normalize the Facebook posts, and measure the amount of employee-directed content as the ratio of employee-related words to all words in a post (similar techniques have been used, see e.g. [42]). We classify a post as being employee-related if it is in the top $10 \%$ of all posts in terms of the use of employee-related words (using top $5 \%$ or top $15 \%$ yields similar results). We aggregate this measure by firm and year in order to capture the total number of employee-related posts (Employee-Related Facebook Posts). We further validate our classifications using Amazon Mechanical Turk (AMT), working with human labelers to manually classify a sample of posts. We treat the hand-classified posts as the training set for a variety of supervised learning models, including naïve Bayes, logistic regression, and support vector machines (SVM). Their classification results largely agree with our simple word counting approach.

Firm Performance Data: Lastly, we link the employer brand captured from job reviews and social media posts to annual financial data from Compustat database. The primary dependent variable in our analysis is firm market value calculated as the sum of the market value of equity (based on stock price at the end of the period) plus the book value of debt. The primary control variables are fixed assets (property plant and equipment), other assets (principally financial assets and intangibles), R\&D assets and advertising assets. The asset values of $R \& D$ and advertising are constructed, respectively, using R\&D and advertising expense in each period through a perpetual inventory method employed in prior research [43].

\subsection{Empirical Methodology}

We primarily draw on the "q theory" of investment [44] suggesting that a firm should invest in assets until the marginal value of an additional dollar invested is equal to a dollar of market value. This theory also implies that the market value of a firm is equal to the sum of the value of its assets, i.e. Market Value $=$ $\sum_{i \in[\text { Asset Types }]} \alpha_{i} A_{i}$, where $A_{i}$ represents the quantity (book value or investment cost) of different assets and $\alpha_{i}$ is the marginal value. Our regression specification is shown in equation (1), and empirical analysis is conducted at the firm $(i)$-year $(t)$ level. Our estimation approach can enable the assessment of long-term value creation, and has previously been employed to study the value of IT-related intangible assets [45, 46, 12] and innovation [47].

Market Value $_{i t}=\alpha+\beta_{1}$ Fixed Asset $_{i t}$

$+\beta_{2}$ Other Assets it $+\beta_{3}$ Advertising Assets A $_{i t}$

$+\beta_{4} R \& D$ Assets $_{i t}+\gamma_{1}$ Job Ratings $_{i t}$

$+\gamma_{2}$ Facebook Posts $_{i t}+\gamma_{3}$ Employee Related

FacebookPosts $_{i t}+\gamma_{4}$ Job Ratings $_{i t} *$

Facebook Posts $s_{i t}+\gamma_{5}$ Job Ratings $s_{i t} *$

Employee Related Facebook Posts it $_{\text {. }}$

+ Controls $_{i t}+\epsilon$ (1)

We begin with the market value model with employer brand measured by employee job ratings (Job Ratings) and estimate its relationship to firm value (Market Value) captured in coefficient $\gamma_{1}$. Next, we probe into how firms' social media activities can interact with their job reviews to jointly build up employer brand. We examine the effect of the general Facebook posts (Facebook Posts) and also some specific category - the posts that discussed employee-related activities on Facebook (Employee-Related Facebook Posts). The interaction effect between those social media posts and job reviews on firm performance can be unveiled through the coefficients $\gamma_{4}$ and $\gamma_{5}$. We consider industry and year fixed effect to control for unobserved heterogeneity across industries and temporal shocks that may influence firm brand values. Some descriptive statistics for our main variables are reported in Table 1.

Table 1. Descriptive Statistics for Main Variables

\begin{tabular}{lll}
\multicolumn{3}{c}{ (\# of Observations=8,374) } \\
\hline Variable & Mean & S.D. \\
\hline Market Value (\$ million) & 9,680 & 15,777 \\
Fixed Assets (\$ million) & 4,016 & 9,697 \\
R\&D Assets (\$ million) & 760.6 & 2,894 \\
Advertising Assets (\$ million) & 681.3 & 2,047 \\
Other Assets (\$ million) & 6,053 & 30,924 \\
Number of Reviews & 8.32 & 15.84 \\
Job Ratings & 3.034 & 0.597 \\
FB Posts & 254.1 & 2,082 \\
Employee-Related FB Posts & 19.66 & 53.74 \\
\hline
\end{tabular}

Note: FB refers to Facebook.

We primarily adopt the Least Absolute Deviations (LAD) regression (also known as quantile regression or median regression) for our market value analyses, following prior work on estimation of market value models in heterogeneous data [12, 46]. The LAD estimator is shown to provide more robust estimates 
than linear models such as Ordinary Least Squares (OLS), in the presence of large observations deviating significantly from the mean [32]. We use a recently developed generalized quantile estimator for panel data that can estimate quantile regression models with fixed effects while appropriately adjusting for the standard errors [48]. This estimator also allows for the inclusion of instrumental variables that we can use in our robustness checks [49].

To ensure our estimations can distinguish the effect of firm employer brand from general corporate brand, we control for various firm-specific characteristics. First, besides firm advertising investment, we include an indicator of whether a firm appears on the Fortune 500 list that could reflect general attributes and investments to build its overall corporate brand [50]. Second, we control for Google Trends search frequency of firm names as a measure of a firm's general online presence. Lastly, we take into account a firm's employee size and average annual salary of employees for general human capital investment.

One concern in our analysis is that higher performing firms may have more slack resources to invest in increasing employee satisfaction. Thus, job ratings can be endogenous. We address this issue using instrumental variables that are derived from hiring networks for each firm in our sample. We access data from BoardEx that covers more than one million profiles of senior executives and directors from companies across various industry sectors and geographic regions. ${ }^{6}$ We examine their employment history and construct firms' hiring networks based on their career movement. Each node in the network is a firm, and each link represents hired directors and executives. Given a focal firm, we use job ratings of its neighboring firms (firms that hired each other) in its network to instrument for its own job ratings. Our instrument is average ratings of its neighboring firms, which can be used as a proxy to measure the ease of access to existing talents and therefore the "cost" of acquiring potential senior-level employees contributing to employer brand [51]. Neighbors in the hiring network are not necessarily competitors as they vary substantially in industries and geographical locations. Therefore, our instruments are less sensitive to common industry or region-specific shocks .

\footnotetext{
${ }^{6}$ https://corp.boardex.com/
}

Table 2. Employer Brand and Market Value

\begin{tabular}{lll}
\hline DV: Market Value & $(1)$ & $(2)$ \\
Method & Quantile/FE & Quantile/FE/IV \\
\hline Fixed Assets & $0.929 * * *$ & $0.929^{* * *}$ \\
& $(0.00287)$ & $(0.0026)$ \\
Other Assets & $0.773 * * *$ & $0.774 * * *$ \\
& $(0.00482)$ & $(0.0287)$ \\
Advertising Assets & $0.717 * * *$ & $0.668^{* * *}$ \\
& $(0.00548)$ & $(0.039)$ \\
R\&D Assets & $0.941 * * *$ & $0.928 * * *$ \\
& $(0.00456)$ & $(0.0358)$ \\
Number of Reviews & $13.56^{* * *}$ & $14.88^{* * *}$ \\
& $(0.216)$ & $(1.373)$ \\
Job Ratings & $34.86^{* * *}$ & $127.0^{* * *}$ \\
& $(8.348)$ & $(33.84)$ \\
Observations & 8,374 & 8,374 \\
\hline \multicolumn{2}{c}{ Note: $* * * \mathrm{p}<0.01, * * \mathrm{p}<0.05, * \mathrm{p}<0.1$}
\end{tabular}

\section{Results}

\subsection{Job Reviews and Market Valuation}

In Table 2, our quantile regression for the panel data shows that on average a one standard-deviation increase in average rating (or increase of 0.60 star in average rating) relates to an increase of approximately $\$ 35$ million in market value, controlling for the level of various assets and variables related to employee salary, time, industry, indicators of general corporate brand strength (Fortune 500, Google Trends search frequency). The asset-related variables show the expected sign and magnitude. The coefficient for fixed assets is approximately 1 and other types of assets value approximately $\$ 0.7-\$ 0.9$ per dollar of book value, comparable to prior estimates from similar empirical framework [46, 12]. Quantile fixed effect estimators with our instrument for job ratings present directionally consistent results. The F-statistic in the first stage regression is above 10 and passes the weak instrument test. We also verify our results by using an alternative specification where Tobin's q serves as the main dependent variable [45] (Table 3). They are consistent with our estimation procedure by placing market value and breakdown of book value on each side of the regression specification.

Our results are robust to alternative methods of aggregating the job ratings, such as combining different sub-categorical ratings. Market value is also higher when a firm has a higher proportion of good ratings ( 4 or 5 stars) but is lower when the firm has a higher proportion of bad ratings ( 1 or 2 stars) (Table 4 ). We also control for those traditional branding measures, such as whether a firm lands on Fortune 500 list and its 
Table 3. Employer Brand and Tobin's q

\begin{tabular}{lll}
\hline DV: Tobin's q & $(1)$ & $(2)$ \\
Method & Quantile/FE & Quantile/FE/IV \\
\hline Number of Reviews & $0.00292 * * *$ & $0.00298 * * *$ \\
& $(0.000942)$ & $(0.000843)$ \\
Job Ratings & $0.102 * * *$ & $0.244 * * *$ \\
& $(0.0243)$ & $(0.0466)$ \\
Observations & 8,374 & 8,374 \\
\hline \multicolumn{2}{c}{ Note: $* * * \mathrm{p}<0.01, * * \mathrm{p}<0.05, * \mathrm{p}<0.1$}
\end{tabular}

Google Trends search frequency, and verify that they do not directionally affect the coefficients of our job rating variables.

Table 4. Employer Brand and Market Value, Alternative Job Ratings

\begin{tabular}{|c|c|c|c|}
\hline & (1) & (2) & (3) \\
\hline & \multirow{2}{*}{\multicolumn{3}{|c|}{$\begin{array}{l}\text { DV: Market Value } \\
\text { Method: Quantile FE }\end{array}$}} \\
\hline & & & \\
\hline \multirow{2}{*}{$\begin{array}{l}\text { Number } \\
\text { Reviews }\end{array}$} & $13.96 * * *$ & $14.12 * * *$ & $14.41 * * *$ \\
\hline & $(0.16)$ & $(0.122)$ & $(0.461)$ \\
\hline \multirow{2}{*}{$\begin{array}{l}\text { Job Ratings, } \\
\text { 4-5 Stars }\end{array}$} & $160.2 * * *$ & & \\
\hline & $(52.48)$ & & \\
\hline \multirow{2}{*}{$\begin{array}{l}\text { Job Ratings, } \\
\text { 1-2 Stars }\end{array}$} & & $-100.7 * * *$ & \\
\hline & & $(30.93)$ & \\
\hline \multirow{2}{*}{$\begin{array}{l}\text { Job Ratings, } \\
\text { CombCateg }\end{array}$} & & & $43.16^{* * *}$ \\
\hline & & & $(9.066)$ \\
\hline Observations & 8,374 & 8,374 & 8,374 \\
\hline
\end{tabular}

To further explore mechanisms for the positive effect, we divide the firms into two categories: labor intensive and capital-intensive firms. We compute the labor factor share and capital factor share for each firm, and then calculate the average for firms at the three-digit SIC code level. We classify industries with higher than average labor factor share as labor intensive industries and others as capital intensive ones. Labor intensive industries generally fall into service, retail and manufacturing, while capital intensive industries are mainly in transportation, mining and utilities. We find that higher job ratings are associated with higher market value for the labor-intensive industries, but not necessarily for the capital-intensive ones (Table 5). These results are consistent with our hypothesis that higher job ratings constitute better employer reputations, particularly if labor constitutes a more important part of the firms' production inputs.
Table 5. Employer Brand and Market Value, Firm Categories

\begin{tabular}{lll}
\hline DV: Market Value & $(1)$ & $(2)$ \\
Method & Quantile/FE & Quantile/FE \\
\hline Sample & Labor & Capital \\
& Intensive & Intensive \\
Number of Reviews & $11.03 * * *$ & $15.47 * * *$ \\
& $(0.177)$ & $(0.0608)$ \\
Job Ratings & $32.67 * * *$ & -4.081 \\
& $(6.077)$ & $(18.27)$ \\
Observations & 4,326 & 4,048 \\
\hline \multicolumn{2}{c}{ Note: $* * * \mathrm{p}<0.01, * * \mathrm{p}<0.05, * \mathrm{p}<0.1$}
\end{tabular}

Apart from the overall ratings across all job categories, we also probe into whether ratings for specific job positions that are commonly associated with higher turnover rate or more crucial to the growth of firm performance can contribute additional values. Specifically, we separately calculate the average ratings for IT positions and non-IT positions, and for R\&D positions and non-RD positions. Employees with technical know-how are more likely to engage in job search activities and consider switching employers [27]. Knowledge workers with specialized skills, such as those involved in scientific discovery and innovation may have similar job activities. The ability to attract and retain these workers could have a strong relationship to firm value [47, 51]. Our results suggest that better job ratings for IT positions and R\&D positions are greatly associated with higher increases in market value $(\mathrm{p}<0.001)$ (Table 6). These results provide additional support to our hypothesis that employer brand is valuable, suggesting that at least part of the relationship is due to the increasing recruitment and retention of high-skill and high-mobility workers.

Table 6. Employer Brand and Market Value, Job Categories

\begin{tabular}{|c|c|c|}
\hline & & \\
\hline \multirow{2}{*}{$\begin{array}{l}\text { DV: Market Value } \\
\text { Method }\end{array}$} & (1) & (2) \\
\hline & Quantile/FE & Quantile/FE \\
\hline \multirow[t]{2}{*}{ Number of Reviews } & $13.84 * * *$ & $13.66 * * *$ \\
\hline & $(0.152)$ & $(0.117)$ \\
\hline \multirow[t]{2}{*}{ Job Ratings, IT } & $56.77 * * *$ & \\
\hline & $(11.48)$ & \\
\hline \multirow[t]{2}{*}{ Job Ratings, non-IT } & $17.99 * *$ & \\
\hline & $(8.297)$ & \\
\hline \multirow[t]{2}{*}{ Job Ratings, R\&D } & & $325.0 * * *$ \\
\hline & & $(33.55)$ \\
\hline \multirow[t]{2}{*}{ Job Ratings, non-R\&D } & & $45.11 * * *$ \\
\hline & & $(8.419)$ \\
\hline Observations & 8,374 & 8,374 \\
\hline
\end{tabular}




\subsection{Social Media for Employer Brand}

Next, we examine whether firms could further improve their employer brand value by engaging in employee-focused social media activities. We estimate quantile regression models that augment our initial market value equation with measures of social media activities - total Facebook posts as well as employee-oriented posts. In Table 7, we find that while the number of Facebook posts, by itself, has no discernable direct effect on market value, it indeed has a strong interaction with employee job ratings. This interaction effect is mostly driven by employee-related posts though the direct effect of employee-relevant content is also not significant. This result is consistent with our prior argument with respect to improved signal accuracy and reliability that can explain why employment-related social media can yield increasing returns related to job reviews. Similarly, the fact that social media activity has no direct effect is consistent with the observation that in isolation, social media posts may be regarded as "cheap talk" without some other signal to reinforce the accuracy of the online messages. Overall, these results support our Hypothesis 2.

Table 7. Employer Brand with Social Media

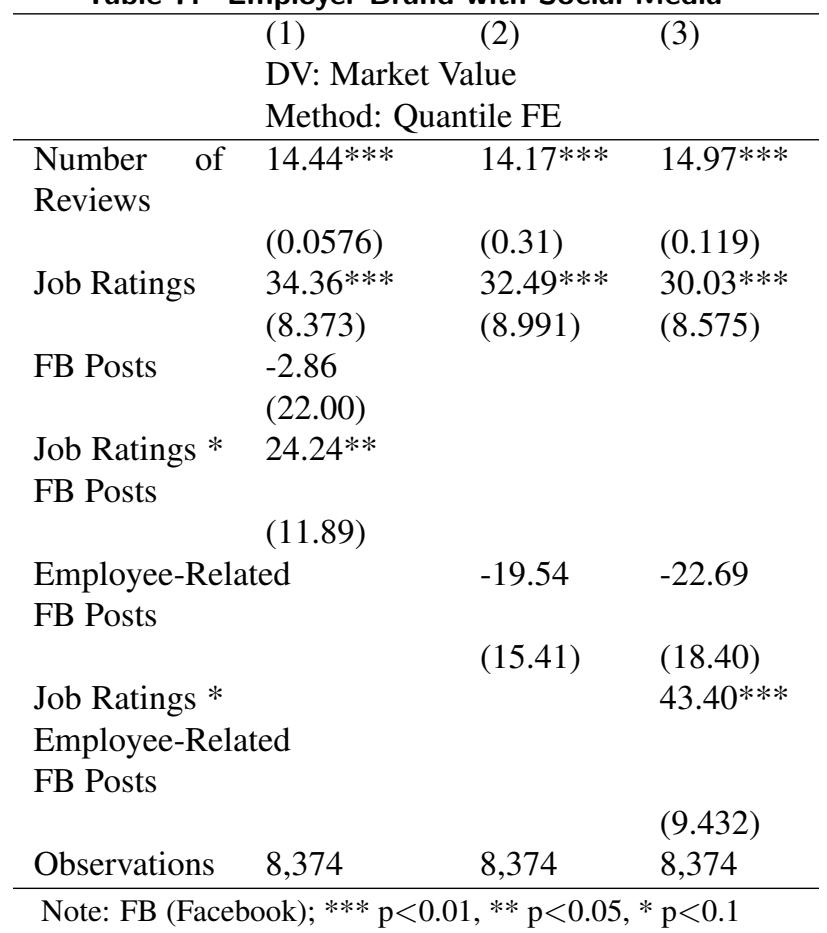

Our preferred explanation for why employer brand should be valued as another intangible asset is that it potentially reduces employee turnover, helping firms retain existing employees. To examine the validity of this mechanism, we examine how job ratings in conjunction with firm social media posts can influence the average length of employment. We adopt a similar estimation framework with average length of employment as dependent variable, controlling for the same firm characteristics as used in prior analyses. In Table 8, we find that higher job ratings are associated with longer average length of employment. There is a strong positive interaction effect between job ratings and employee-oriented social media posts. Overall, these results provide additional empirical support to our hypothesis that stronger employer brand relates to higher market value, enabling firms to better retain existing talent and reduce cost of potentially replacing employees.

Table 8. Employer Brand with Social Media, Mechanism

(1)

DV: Length of Employment Method: Quantile FE

\begin{tabular}{|c|c|c|}
\hline \multirow{2}{*}{$\begin{array}{l}\text { Number } \\
\text { Reviews }\end{array}$} & $0.00687 * * *$ & $0.00661 * * *$ \\
\hline & $(0.000111)$ & $\left(6.68 \times 10^{-5}\right)$ \\
\hline Job Ratings & $\begin{array}{l}0.0663 * * * \\
(0.00728)\end{array}$ & $\begin{array}{l}0.0504 * * * \\
(0.00632)\end{array}$ \\
\hline $\begin{array}{l}\text { Employee-Related } \\
\text { FB Posts }\end{array}$ & & $0.465 * * *$ \\
\hline $\begin{array}{l}\text { Job Ratings * } \\
\text { Employee-Related } \\
\text { FB Posts }\end{array}$ & & $\begin{array}{l}(0.0157) \\
0.0468 * * *\end{array}$ \\
\hline Observations & 8,374 & $\begin{array}{l}(0.0110) \\
8,374\end{array}$ \\
\hline
\end{tabular}

\section{Conclusion and Discussion}

In this study, we examine how online job reviews and social media posts can jointly constitute firms' word-of-mouth among employees (employer brand) as another important intangible asset to influence firm market value. Our study shows that better job ratings are associated with higher firm market value, particularly in labor intensive industries and for job positions with higher mobility (e.g. IT positions) and that are harder to replace (e.g. R\&D positions). Furthermore, we demonstrate that firms can reinforce the value of their employer brand, by providing complementary information on social media. By showing the relevance of social media content to employer brand and firm market value, our findings provide novel insights on firm social media strategies 
relating to integrating social media into decision makings that involve multiple function units of the firm instead of the initial focus of social media as a marketing channel [32]. In addition, we also show that one of the mechanisms through which employer brand can create more value for firms is retention of their employees, thus enabling the reduction of their spending to search new employees to replace existing ones.

Our findings also offer several important implications for managers concerned with establishment of a favorable employer brand to improve firm performance. First, employer brand is distinct and can have a significant effect on retention. Second, employer brand is another type of intangible asset for firms. It is beneficial for firms to leave a positive impression for their employees that they provide a good workplace environment and a fit for potential job candidates [20]. Third, firms can leverage other digital channels such as social media to exhibit and communicate more employee-relevant activities that were behind the scenes in the past. They should have coordinated strategies, maintaining a consistent positive employer brand image across various information channels.

This study has some limitations that can also offer new directions for future research explorations. Though Facebook is recognized as the most popular social media platform ${ }^{7}$ and corporate Facebook pages can be used to measure employer brand, firms also actively manage their business profiles on other social media platforms such as Twitter and YouTube [33], and even more job-oriented platform such as LinkedIn. Therefore, as firms can showcase more employee activities and workplace environment across various digital platforms, future studies can be undertaken to validate our findings in other social media channels where more employee-related posts by firms can be uncovered and well identified. It's crucial to analyze firm-generated content on a large scale to gain a deeper understanding of the overall employer brand image [6]. In addition, our study does not directly examine another important role that a positive employer brand can play in acquiring new employees as a good fit for firms. Future research could be conducted to collect and analyze profiles of new hires attracted by employer brand and their influence on firm performance.

\section{References}

[1] T. Ambler and S. Barrow, "The employer brand," Journal of Brand Management, vol. 4, no. 3, pp. 185-206, 1996.

[2] W. Burgess, "A bad reputation costs a company at least

\footnotetext{
${ }^{7}$ https://www.statista.com/statistics/272014/global-social-networks -ranked-by-number-of-users/; https://www.statista.com/statistics/265773 /market-share-of-the-most-popular-social-media-websites-in-the-us/
}

10\% more per hire," Harvard Business Review, 2016.

[3] R. Mosley, "Ceos need to pay attention to employer branding," Harvard Business Review, vol. 11, p. 2015, 2015.

[4] D. A. Aaker, "Measuring brand equity across products and markets.," California Management Review, vol. 38, no. 3, 1996.

[5] K. L. Keller, "Conceptualizing, measuring, and managing customer-based brand equity," Journal of Marketing, vol. 57, no. 1, pp. 1-22, 1993.

[6] Y. Hu, A. Xu, Y. Hong, D. Gal, V. Sinha, and R. Akkiraju, "Generating business intelligence through social media analytics: measuring brand personality with consumer-, employee-, and firm-generated content," Journal of Management Information Systems, vol. 36, no. 3, pp. 893-930, 2019.

[7] J. A. Chevalier and D. Mayzlin, "The effect of word of mouth on sales: Online book reviews," Journal of Marketing Research, vol. 43, no. 3, pp. 345-354, 2006.

[8] C. Dellarocas, X. M. Zhang, and N. F. Awad, "Exploring the value of online product reviews in forecasting sales: The case of motion pictures," Journal of Interactive Marketing, vol. 21, no. 4, pp. 23-45, 2007.

[9] C. Forman, A. Ghose, and B. Wiesenfeld, "Examining the relationship between reviews and sales: The role of reviewer identity disclosure in electronic markets," Information Systems Research, vol. 19, no. 3, pp. 291-313, 2008.

[10] X. Li and L. M. Hitt, "Self-selection and information role of online product reviews," Information Systems Research, vol. 19, no. 4, pp. 456-474, 2008.

[11] F. Zhu and X. Zhang, "Impact of online consumer reviews on sales: The moderating role of product and consumer characteristics," Journal of Marketing, vol. 74, no. 2, pp. 133-148, 2010.

[12] E. Brynjolfsson, L. M. Hitt, and S. Yang, "Intangible assets: Computers and organizational capital," Brookings Papers on Economic Activity, vol. 2002, no. 1, pp. 137-181, 2002.

[13] A. Edmans, "Does the stock market fully value intangibles? employee satisfaction and equity prices," Journal of Financial Economics, vol. 101, no. 3, pp. 621-640, 2011.

[14] M. Kokkodis and P. G. Ipeirotis, "Reputation transferability in online labor markets," Management Science, vol. 62, no. 6, pp. 1687-1706, 2016.

[15] A. Moreno and C. Terwiesch, "Doing business with strangers: Reputation in online service marketplaces," Information Systems Research, vol. 25, no. 4, pp. 865-886, 2014.

[16] M. Huang, P. Li, F. Meschke, and J. P. Guthrie, "Family firms, employee satisfaction, and corporate performance," Journal of Corporate Finance, vol. 34, pp. 108-127, 2015.

[17] X. Ye and P. Tambe, "Why do high-tech firms offer perks at work?," 2015.

[18] N. Archak, A. Ghose, and P. G. Ipeirotis, "Deriving the pricing power of product features by mining consumer reviews," Management Science, vol. 57, no. 8, pp. 1485-1509, 2011.

[19] P. A. Diamond, "Mobility costs, frictional unemployment, and efficiency," Journal of Political Economy, vol. 89, no. 4, pp. 798-812, 1981. 
[20] L. T. Solutions, "Why your employer brand matters," https://business.linkedin.com/content/dam/business/ talent-solutions/global/en_US/site/pdf/datasheets/ linkedin-why-your-employer-brand-matters-en-us.pdf, 2012.

[21] P. Milgrom and J. Roberts, "The economics of modern manufacturing: Technology, strategy, and organization," American Economic Review, pp. 511-528, 1990.

[22] S. Zuboff, In the Age of the Smart Machine: The Future of Work and Power. USA: Basic Books, Inc., 1988

[23] B. L. Connelly, S. T. Certo, R. D. Ireland, and C. R. Reutzel, "Signaling theory: A review and assessment," Journal of Management, vol. 37, no. 1, pp. 39-67, 2011.

[24] D. M. Kreps and R. Wilson, "Reputation and imperfect information," Journal of Economic Theory, vol. 27, no. 2 , pp. 253-279, 1982.

[25] A. Vomberg, C. Homburg, and T. Bornemann, "Talented people and strong brands: The contribution of human capital and brand equity to firm value," Strategic Management Journal, vol. 36, no. 13, pp. 2122-2131, 2015.

[26] A. Drexler and A. Schoar, "Do relationships matter? evidence from loan officer turnover," Management Science, vol. 60, no. 11, pp. 2722-2736, 2014.

[27] P. Tambe and L. M. Hitt, "Job hopping, information technology spillovers, and productivity growth," Management Science, vol. 60, no. 2, pp. 338-355, 2014.

[28] D. L. Shapiro, P. Hom, W. Shen, and R. Agarwal, "How do leader departures affect subordinates' organizational attachment? a 360-degree relational perspective," Academy of Management Review, vol. 41, no. 3, pp. 479-502, 2016.

[29] J. L. Cotton and J. M. Tuttle, "Employee turnover: A meta-analysis and review with implications for research," Academy of Management Review, vol. 11, no. 1, pp. 55-70, 1986.

[30] M. S. Direnzo and J. H. Greenhaus, "Job search and voluntary turnover in a boundaryless world: A control theory perspective," Academy of Management Review, vol. 36, no. 3, pp. 567-589, 2011.

[31] M. A. Huselid, "The impact of human resource management practices on turnover, productivity, and corporate financial performance," Academy of Management Journal, vol. 38, no. 3, pp. 635-672, 1995.

[32] L. Hitt, F. Jin, and L. Wu, "Data skills and value of social media: Evidence from large-sample firm value analysis," 2015

[33] F. Jin, A. Wu, and L. Hitt, "Social is the new financial: How startup social media activity influences funding outcomes," in Academy of Management Proceedings, vol. 1, p. 13329, Academy of Management Briarcliff Manor, NY 10510, 2017.

[34] X. Luo, J. Zhang, and W. Duan, "Social media and firm equity value," Information Systems Research, vol. 24, no. 1, pp. 146-163, 2013

[35] R. Divol, D. Edelman, and H. Sarrazin, "Demystifying social media," McKinsey Quarterly, 2012.

[36] M. Yang, Y. Ren, and G. Adomavicius, "Understanding user-generated content and customer engagement on facebook business pages," Information Systems Research, vol. 30, no. 3, pp. 839-855, 2019.
[37] K.-Y. Goh, C.-S. Heng, and Z. Lin, "Social media brand community and consumer behavior: Quantifying the relative impact of user-and marketer-generated content," Information Systems Research, vol. 24, no. 1, pp. 88-107, 2013

[38] C. Dellarocas, "Strategic manipulation of internet opinion forums: Implications for consumers and firms," Management Science, vol. 52, no. 10, pp. 1577-1593, 2006.

[39] M. Luca and G. Zervas, "Fake it till you make it: Reputation, competition, and yelp review fraud," Management Science, vol. 62, no. 12, pp. 3412-3427, 2016.

[40] D. Mayzlin, Y. Dover, and J. Chevalier, "Promotional reviews: An empirical investigation of online review manipulation," American Economic Review, vol. 104, no. 8, pp. 2421-55, 2014.

[41] D. M. Blei, A. Y. Ng, and M. I. Jordan, "Latent dirichlet allocation," Journal of Machine Learning Research, vol. 3, no. Jan, pp. 993-1022, 2003.

[42] L. Wu, "Social network effects on productivity and job security: Evidence from the adoption of a social networking tool," Information Systems Research, vol. 24, no. 1, pp. 30-51, 2013.

[43] B. H. Hall, "The manufacturing sector master file: 1959-1987," tech. rep., National Bureau of Economic Research, 1990.

[44] J. Tobin, "A general equilibrium approach to monetary theory," Journal of Money, Credit and Banking, vol. 1, no. 1, pp. 15-29, 1969.

[45] A. S. Bharadwaj, S. G. Bharadwaj, and B. R. Konsynski, "Information technology effects on firm performance as measured by tobin's q," Management Science, vol. 45, no. 7, pp. 1008-1024, 1999.

[46] E. Brynjolfsson and S. Yang, "The intangible costs and benefits of computer investments: Evidence from the financial markets," in Atlanta, Georgia: Proceedings of the International Conference on Information Systems, 1999.

[47] M. Simeth and M. Cincera, "Corporate science, innovation, and firm value," Management Science, vol. 62, no. 7, pp. 1970-1981, 2016.

[48] D. Powell, "Quantile regression with nonadditive fixed effects," Quantile Treatment Effects, pp. 1-28, 2016.

[49] V. Chernozhukov and C. Hansen, "Instrumental variable quantile regression: A robust inference approach," Journal of Econometrics, vol. 142, no. 1, pp. 379-398, 2008.

[50] M. Klock and P. Megna, "Measuring and valuing intangible capital in the wireless communications industry," The Quarterly Review of Economics and Finance, vol. 40, no. 4, pp. 519-532, 2000.

[51] L. Wu, L. Hitt, and B. Lou, "Data analytics, innovation, and firm productivity," Management Science, vol. 66, no. 5, pp. 2017-2039, 2020. 